\title{
LA SUERTE EPISTÉMICA COMO CARENCIA DE CONTROL Y SU VERTIENTE EXTERNISTA
}

\author{
Guillermo Marín Penella \\ guillermo1998zgz@gmail.com \\ Universidad de Granada
}

\section{RESUMEN}

Este artículo plantea una defensa a la noción de suerte epistémica como carencia de control, considerándola mejor que otras nociones modales o probabilísticas. Esta orientación en la definición va a ser defendida con algunos cambios basados en la noción de externismo y en la noción de riesgo, con el objetivo de salvar una serie de problemas planteados, por ejemplo, por Jennifer Lackey. Por último, la noción de suerte epistémica como carencia de control en su vertiente externista se relacionará con la cuestión de la genealogía de la suerte, propuesta recientemente por Amia Srinivasan.

Palabras clave: suerte epistémica, carencia de control, riesgo, externismo, genealogía de la suerte.

\section{EPISTEMIC LUCK AS LACK OF CONTROL AND ITS EXTERNIST BRANCH}

\section{Abstract}

This paper proposes a defense of the notion of epistemic luck as lack of control, considering it better than the modal and the probabilistic notions. This orientation in the definition will be defended with some changes based on the notion of externism and on the notion of risk, with the aim of saving a serie of problems proposed, for example, by Jennifer Lackey. Finally, the luck epistemic's notion as lack of control in its externist branch will be related to the question of the luck's genealogy, recently proposed by Amia Srinivasan.

KEYwORDs: Epistemic luck, lack of control, risk, externism, genealogy of luck. 


\section{INTRODUCCIÓN}

Desde los contraejemplos de Gettier ${ }^{1}$ la concepción tripartita del conocimiento ha sido prácticamente desterrada. No obstante, este destierro ha venido acompańado de un aumento de la importancia que tiene la suerte epistémica, que se sitúa en el núcleo central de nuestras consideraciones sobre epistemología, algo que puede resumirse en la afirmación realizada por J. Dancy, según la cual «en la concepción tripartita del conocimiento no había nada que excluyera el conocimiento por suerte» $\aleph^{2}$. En esta situación, Duncan Pritchard ${ }^{3}$, uno de los más prestigiosos filósofos que han tratado la cuestión de la suerte epistémica, ha afirmado que una teoría en epistemología debe dar una consideración del conocimiento que cumpla con dos intuiciones maestras: el conocimiento debe evitar que nuestra creencia sea verdadera por una cuestión de suerte (intuición antisuerte) y, además, todo conocimiento ha de ser el resultado de una habilidad cognitiva del agente que conoce (intuición de la habilidad). Estas dos intuiciones deben ser satisfechas para lograr una definición de conocimiento que sea informativa, no circular, y con la que podremos dar acomodo a otras intuiciones epistemológicas, conformando así lo que Pritchard llama "proyecto analítico». Así pues, cualquier teoría sobre la epistemología debe garantizar ambas intuiciones, algo que pretendo realizar a continuación.

\section{SUERTE EPISTÉMICA Y SUERTE COMO RIESGO}

En los debates que buscan dar una solución a la intuición antisuerte (a pesar de que en algunos casos la solución sea el rechazo de esa intuición), se da una preocupación central, que es la de la caracterización de la noción de suerte epistémica. Esta caracterización se hace en la literatura contemporánea bajo tres distintos enfoques: definiciones modales, definiciones probabilísticas y definiciones de la suerte epistémica como carencia de control.

${ }^{1}$ V. Edmund Gettier, «¿Una creencia verdadera justificada es conocimiento?», Disputatio. Philosophical Research Bulletin, n. ${ }^{\circ} 3$, 2013, pp. 185-193, trad. Paulo Vélez León.

${ }_{2}^{2}$ Jonathan DANCY, Introducción a la epistemología contemporánea, Madrid, Tecnos, 2007, p. 158.

3 Duncan Pritchard, «Anti-Luck Virtue Epistemology», Journal of Philosophy, vol. 109, n. ${ }^{\circ}$, 2012, pp. 247-279. 
Las definiciones modales han tenido mucha importancia en la literatura actual a través de la figura de Duncan Pritchard ${ }^{45}$, que caracteriza la suerte a través de dos condiciones clave:

C1. Cuando un suceso es cuestión de suerte, ese suceso ha ocurrido en el mundo actual, pero hay una serie de mundos cercanos posibles en los que ese mismo suceso no ocurriría; manteniendo las condiciones iniciales iguales.

C2. Cuando un suceso es cuestión de suerte, entonces ese evento es significativo para un agente en cuestión.

Esta teoría de la suerte epistémica puede explicar eventos paradigmáticos como el de la lotería y nos permite saber por qué la gente juega a este juego de azar. Bajo una definición probabilística de la suerte, no podríamos entender los impulsos que las personas tienen de gastar parte de su dinero, ya que las probabilidades de ganar son ínfimas. Sin embargo, con una caracterización modal, se puede observar que la gente tiende a jugar a la lotería porque el mundo posible en que una persona gana es un mundo posible muy cercano al mundo en el que una persona pierde. Esto marca una diferencia fundamental entre las aproximaciones modales y las probabilísticas y es el punto explicativo fuerte de las primeras con respecto de las segundas.

Ganar la lotería sería entonces cuestión de suerte para un agente $S$ porque, a pesar de haber ocurrido, en la mayoría de los mundos cercanos posibles $S$ pierde la lotería; manteniendo las condiciones iniciales iguales (aceptando que $S$ compra la lotería, que la lotería no va a ser amañada...).

Esta teoría tiene el reto de explicar las cuestiones relacionadas con la cantidad de esos distintos mundos posibles, esto es, habría que marcar cuántos de esos mundos cercanos posibles son necesarios para que el suceso sea considerado como ocurriendo por cuestión de suerte. Pritchard ${ }^{6}$ afirma que cuando la mayoría de esos mundos posibles son contrarios a lo que ha ocurrido (como en el caso de la lotería), la suerte epistémica está garantizada. Cuando en la mitad de los mundos posibles lo que ha sucedido sucede, y en la otra mitad no, como en un concurso de preguntas en el que hay que elegir una pregunta correcta entre dos (eligiendo de manera azarosa y acertando), también consideramos que esa elección concreta ha sido cuestión de suerte. Por otra parte, siempre que haya más mundos posibles en los que sucede lo que ocurre en el mundo actual (como cuando elegimos en un concurso una pregunta correcta entre 3 siendo dos de ellas correctas) que mundos posibles en los que no ocurre, no podemos considerar que el evento haya sido cuestión de suerte según

${ }^{4}$ Duncan Pritchard, Epistemic luck, Oxford, Clarendon Press, 2005.

5 Duncan Pritchard, «The modal account of luck», en The philosophy of luck, ed. Duncan Pritchard \& Lee John Whittington, Londres, Routledge, 2015.

${ }^{6}$ Duncan Pritchard, Epistemic luck. 
Pritchard. Además, hay que tener en cuenta que poner un límite demasiado alto, como por ejemplo exigir que no haya ningún mundo posible contrario a lo que sucede, podría hacer que cualquier suceso epistémico fuera considerado como una cuestión de suerte (algo que nos llevaría a situaciones indeseadas), pues casi siempre hay mundos posibles y cercanos que juegan un papel en nuestras atribuciones.

Ahora bien, considero que hay algunos ejemplos en los que, no cumpliendo la definición modal de Pritchard, los encontramos como afortunados?:

\section{Concurso filosófico}

Cipriano va a un concurso en el que se hace una pregunta del tipo «¿Cuál de los siguientes nombres es $\mathrm{x}$ ?» y se da una serie de seis posibilidades. Se hacen cinco preguntas de este tipo (de modo que se juegan cinco rondas). La idea del concurso es que vaya eliminando aquellos nombres que sí cumplen con la condición $\mathrm{x}$, hasta que quede el nombre que no es $\mathrm{x}$. Cada concursante, además, puede retirarse y llevarse el dinero acumulado con cada nombre que señale correctamente. El día en el que a Cipriano le toca acudir, la última pregunta (ya ha pasado cuatro preguntas anteriores de manera satisfactoria) es "¿Cuál de los siguientes nombres es filósofo?» y se dan seis nombres, a saber: Bertrand Russell, Sören Kierkegaard, Friedrich Nietzsche, Baruch Spinoza, Hiparquía y Marvin Harris. Lo cierto es que Cipriano no sabe absolutamente nada de filosofía, ni tampoco de antropología, de modo que la única solución que le queda es responder al azar con la esperanza de acertar y poder llevarse el dinero que ha obtenido en las preguntas anteriores. Cipriano tira un dado de seis caras, responde y señala a Baruch Spinoza como filósofo. Acierta y se lleva el premio acumulado en las preguntas anteriores.

A pesar de que Cipriano ha acertado la pregunta y de que en la mayoría de los mundos posibles cercanos (manteniendo las condiciones iniciales iguales) también se llevaría el dinero, pues solo en uno de los seis mundos posibles Cipriano pierde el dinero de rondas anteriores, identificamos que ha tenido suerte a la hora de responder y prueba de ello es que no sabe cuál de los nombres es de un filósofo y cuál es de un antropólogo. El puro azar (método que había utilizado Cipriano para responder) demuestra que el suceso del acierto es afortunado. No es, por lo tanto, el conocimiento de Cipriano el que le ha permitido pasar de ronda y llevarse el dinero, sino la suerte de que el dado le dijese que marcara el nombre de Baruch Spinoza. Por lo tanto, podemos concluir que la definición aportada por Pritchard no satisface alguna de nuestras intuiciones con respecto a la suerte epistémica y que ha de ser dejada de lado, por el hecho de no explicar bien la problemática relativa a la cantidad de mundos posibles cercanos necesarios para identificar un evento como relacionado con la suerte.

7 Utilizo aquí «afortunado» como sinónimo de «suertudo». Ambas palabras deben entenderse como haciendo referencia a que algo ha sido cuestión de suerte, en su sentido más intuitivo. 
Ahora bien, la cercanía de los mundos posibles ha sido una característica también discutida por parte de algunos autores como Adam Carter y Martin Peter$\operatorname{son}^{8}$, quienes pretenden defender también una caracterización modal de la suerte epistémica. Su estrategia es la de considerar un ejemplo límite de suerte en el que un mundo posible más haría que el evento sucediese por cuestión de suerte. A este evento límite se le añade un mundo posible lejano opuesto, de tal modo que el evento, intuitivamente, debería ser considerado como afortunado. La definición de Pritchard, según los autores, no permite esto, ya que solo son considerables los mundos posibles cercanos. Por ello, Carter y Peterson hacen una reformulación en la que se incluya la naturaleza gradual de la suerte, con la que pretenden salvar el contraejemplo de Jennifer Lackey ${ }^{9}$, según el cual Sophie, que está a punto de morir, decide esconder un tesoro, empleando tan solo dos criterios: que esté en el noroeste de la isla y que puedan nacer rosas. Solo hay una zona en la isla que cumpla estas condiciones, y el tesoro es enterrado allí. Un mes más tarde, Vincent pretende plantar una rosa en honor a su madre, y descubre el mejor lugar para que las rosas crezcan, que es precisamente el lugar donde Sophie escondió su tesoro. La idea es que, mientras que el hecho de que Vincent encontrara el tesoro es afortunado (puesto que no tenía ni idea del emplazamiento del mismo), es excluido como afortunado por la definición de Pritchard, ya que no hay ningún lugar de la isla más apropiado para que Vincent plantara la rosa en honor a su madre (y por tanto en la mayoría de los mundos posibles cercanos, Vincent encuentra el tesoro).

La solución de los autores ${ }^{10}$ se basa en considerar la suerte no solo a partir del número de mundos posibles, sino también de la cercanía y la lejanía de los mismos. Un evento sería afortunado entonces si ocurriese en el mundo actual, pero su probabilidad modal ponderada tendría que estar por debajo de un límite apropiado, valorando que la probabilidad modal ponderada decrece a medida que aumenta la distancia del mundo actual y que la suerte disminuye a medida que aumentan los mundos en los que el evento sucede. Así pues, según los autores, Sophie y Vincent cavan en el mismo punto de la isla en muchos mundos posibles, pero hay una serie de mundos lejanos posibles (que Vincent muera, que nunca descubriese la isla, etc.) que nos permiten identificar el suceso como afortunado.

No obstante, considero que la posición de Carter y Petersen también cae bajo nuestro contraejemplo. Hemos de recordar que en el suceso satisfactorio de Cipriano se plantean seis mundos posibles cercanos en los que cinco soluciones son acertadas y una no. Cipriano es afortunado en una gran mayoría de los mundos posibles y no parece en principio que ninguna serie de mundos lejanos posibles puedan salvar nuestra identificación del caso como afortunado. Más bien parece que los mundos posibles lejanos podrían ayudar a identificar suerte epistémica en casos

${ }^{8}$ Adam Carter \& Martin Petersen, «The Modal Account of Luck Revisited», Synthese, 194, 2016, pp. 2175-2184. pp. 255-267.

9 Jennifer LaCKey, "What is not Luck», Australian Journal of Philosophy, vol. 86, 2008,

10 Adam Carter \& Martin Petersen, op. cit., p. 2181. 
límite donde algunos mundos posibles lejanos nos hagan cambiar nuestras intuiciones. Esto no es lo que sucede en el caso de Cipriano (ni tampoco, a mi juicio, en el de Jennifer Lackey). Cipriano tendría que haber puesto su cognición a funcionar para que identificásemos el evento como no afortunado, pero no fue así, sino que eligió a Spinoza tirando un dado de seis caras. Ninguna serie de mundos posibles lejanos puede cambiar el hecho de que en la mayoría de los mundos posibles cercanos Cipriano acierta por cuestión de suerte.

Por todo esto, mi enfoque de la suerte epistémica no será modal, sino que se valorarán otras caracterizaciones.

\section{AproximaCión PROBABILÍSTICA A LA SUERTE EPISTÉMICA}

De la aproximación probabilística hay pocas caracterizaciones en epistemología, aunque bastantes en otras ramas como la filosofía de la ciencia o en otras disciplinas alejadas de la filosofía. Peter Baumann ${ }^{11}$ es uno de los pocos autores que dan una definición bajo estas características dentro del campo de la filosofía, afirmando que un evento es afortunado solo cuando es altamente improbable que eso suceda, pero valorando «improbable» como algo subjetivo. Así pues, una definición de la suerte para Peter Baumann ha de valorar contextos, esto es, probabilidades condicionales. Si dentro de unos determinados estándares, un evento concreto sobrepasa una serie de límites (expresados de manera probabilística), entonces ese evento es afortunado. Por ejemplo, no tiene sentido para Baumann pensar sobre la probabilidad de que haga un día soleado en general, sino que hay que pensar si ese día soleado se va a dar en agosto en una de las preciosas playas de Cádiz o más bien en la lluviosa costa gallega un día de otoño.

Otra aproximación en este sentido la da Jesús Navarro ${ }^{12}$, mostrando una caracterización probabilística en términos de riesgo a través de su ejemplo de un cirujano que tiene un $95 \%$ de posibilidades de que las operaciones que realiza salgan bien (y un 5\% de que el paciente muera). La idea es que si un paciente firma su aceptación para ser operado y desgraciadamente muere, el cirujano no debería rendir cuentas con la justicia, puesto que esa muerte del paciente se engloba dentro del $5 \%$ marcado y firmado. La familia, según Jesús Navarro, no podría reclamar nada, ni tampoco el cirujano habría cometido una falta ética, puesto que el paciente ha sido, simplemente, víctima de la mala suerte ${ }^{13}$.

Dicho esto, voy a plantear un contraejemplo a este tipo de acercamiento a la suerte epistémica muy relacionado con la cuestión ética y la suerte. Voy a intentar

11 Peter Baumann, «No Luck with Knowledge? On a Dogma of Epistemology», Philosophy and Phenomenical Research, vol. 89, n. ${ }^{\circ}$ 3, 2014, pp. 523-551.

12 Jesús Navarro, «Epistemic Luck and Epistemic Risk», en prensa.

13 Se debe destacar que Jesús Navarro no se compromete con ninguna visión de la suerte epistémica en su texto y que los ejemplos que expone son para mostrar la validez del giro del riesgo, que veremos después. 
mostrar cómo un paciente del cirujano anterior puede mantenerse dentro de unos determinados límites probabilísticos y al mismo tiempo no ser víctima de la mala suerte, aunque aquello que le suceda sea muy improbable:

\section{Cirujano con las manos de mantequilla}

Supongamos que introducimos una cámara imperceptible dentro de la consulta de este cirujano. Miramos cada una de sus operaciones en el plazo de un ańo, y descubrimos que han muerto el $4 \%$ de los pacientes que este cirujano ha operado. No obstante, si miramos de manera cercana las grabaciones, nos damos cuenta de que el cirujano ha operado de manera satisfactoria a todos los pacientes, y que ese $4 \%$ de los pacientes ha muerto por mala suerte excepto uno de ellos, que murió porque al cirujano se le resbaló el bisturí de las manos y fue a parar al corazón del paciente. Supongamos que el hecho de que un bisturí se resbale accidentalmente de las manos no es algo que les podamos aceptar a nuestros cirujanos. Lo lógico en una situación así es que la familia del paciente fallecido, al ver el vídeo, se enfadara profundamente y decidiera demandar a este terrible cirujano que no sabe mantener un bisturí entre sus manos mientras realiza una operación a corazón abierto. No ha sido, simplemente, una cuestión de suerte que el paciente haya muerto, sino una falta de pericia de un cirujano al que no se le pueden tolerar este tipo de fallos, a pesar de que el hecho haya sido improbable.

En este contraejemplo podemos ver entonces cómo la caracterización probabilística dada por Jesús Navarro no es adecuada para explicar algunos ejemplos que no son suerte epistémica y cómo puede hacer, además, que algunos médicos continúen en sus trabajos cuando no deben hacerlo. De hecho, el contraejemplo del cirujano con las manos de mantequilla también nos sirve para contraponernos a la concepción de Baumann, puesto que no podemos aceptar que un evento (la muerte de un paciente) que sucede bajo unas determinadas características condicionales (que el cirujano sea un verdadero profesional, que las condiciones de la operación sean óptimas...) sea un evento fortuito cuando el cirujano ha cometido un error enorme y que se supone que no debe cometer cuando está operando a un paciente, a pesar de que cumpla en el conjunto de sus operaciones con el porcentaje marcado para las operaciones realizadas por los cirujanos. Es un evento, pues, que, a pesar de ser improbable, no podemos decir de él que haya sido mala suerte, sino que afirmamos que ha sido una falta de pericia grave del cirujano, al que deberíamos poder procesar por ello, pues es algo que no se les debe permitir a los cirujanos. Es por esto que una definición probabilística no es adecuada para enfrentarnos a la suerte epistémica.

\section{LA SUERTE EPISTÉMICA COMO CARENCIA DE CONTROL}

En este punto, hemos de considerar una tercera caracterización que define la suerte como carencia de control del agente con respecto a una serie de eventos. Bajo este tipo de aproximaciones podemos colocar a Fernando Broncano-Berrocal 
como uno de los autores que han defendido una noción de suerte epistémica de estas características. El autor afirma que «un evento $\mathrm{E}$ es afortunado para $\mathrm{S}$ si y solo si $\mathrm{E}$ ocurre y $S$ está en riesgo con respecto de $\mathrm{E}$. $\mathrm{S}$ está en riesgo con respecto de $\mathrm{E}$ si y solo si (I) $S$ tiene un interés N, (II) si E ocurriese, habría algún efecto objetivamente positivo o negativo sobre N, y (III) S tiene una carencia de control sobre E. La condición (III) debe ser entendida como sigue: $S$ tiene carencia de control sobre E si y solo si tiene carencia de control efectiva o carencia de control monitoreada, o ambas $»^{14}$. El control efectivo de A sobre B se da cuando:

(I) es un objetivo de A que B esté en un cierto estado $S$,

(II) A está en disposición de llevar a B a $\mathrm{S}$,

(III) B está en $S$ por la disposición de A de llevar a B a $S$.

Por otro lado, el control monitoreado de A sobre B se da cuando se cumple con dos componentes:

(I) A registre información sobre B (esta es la información epistémica o componente informacional del monitoreo) y

(II) que la información que $\mathrm{A}$ registra sobre $\mathrm{B}$ permita a $\mathrm{A}$ iniciar, parar o continuar alguna acción que contribuya a un objetivo relevante ${ }^{15}$.

Por ejemplo, conducir un coche es algo que se incluye dentro del control efectivo, mientras que un médico que comprueba si un paciente está bien después de una caída tiene un control monitoreado.

Hemos de fijarnos en que esta posición salva los contraejemplos explicitados anteriormente. Cipriano ha tenido suerte en su elección dentro del concurso porque no tenía ningún control sobre su respuesta (de hecho la decidió tirando un dado de seis caras). Además, el cirujano con las manos de mantequilla no ha tenido mala suerte en su operación, puesto que se considera que un cirujano debe tener un control explicitado en forma de un pulso firme y una sujeción del bisturí adecuada (son habilidades que un cirujano debe tener para que se le dé la posibilidad de ejercer como cirujano, esto es, para ser un verdadero cirujano). Una concepción como esta también es capaz de explicar algunos contraejemplos que se le han hecho a la concepción de la carencia de control por parte de Jennifer Lackey ${ }^{16}$, como es el caso de la trabajadora de demolición. En este ejemplo, Ramona va a pulsar un botón que hará explotar un almacén abandonado. Sin embargo, Ramona no sabe que un ratón ha roto el circuito horas antes, y pulsa el botón al mismo tiempo que otro trabajador se apoya fortuitamente en la parte destrozada por el ratón y una parte metálica

${ }^{14}$ Fernando Broncano-BerRrocal, «Luck as Risk and Lack of Control Account of Luck», Metaphilosophy, vol. 46, n. ${ }^{\circ} 1,2015$, pp. 1-25.

15 Ibid., p. 18.

${ }^{16}$ Jennifer Lackey, op. cit. 
de su chaqueta permite que la demolición se lleve a cabo. El evento es identificado como por cuestión de suerte, pero no diríamos que Ramona no es responsable de la explosión. La idea que permite salvar este contraejemplo es que, aunque Ramona sí tiene un control efectivo sobre la explosión, no tiene el control monitoreado, y en algunas ocasiones es necesario tener ambos tipos de control.

Es notable también que una concepción así tiene algunas ventajas teóricas sobre las otras concepciones en relación con las dos intuiciones que nombraba en la introducción, puesto que el control sobre algo supone ya una cierta habilidad. Centrarse a la hora de atribuir suerte epistémica en el agente y en su control efectivo o de monitoreo sobre una determinada serie de cosas nos permite pensar que tener control sobre algo implica una cierta manera de desenvolver una habilidad cognitiva de algún tipo, lo que ciertamente da mejores disposiciones a la hora de relacionar las dos intuiciones maestras de la epistemología. De este modo, el médico que tiene control sobre un paciente lo tiene precisamente por el desempeńo de una serie de habilidades que el médico tiene (conocimientos sobre medicina). Algo parecido pasa con conducir un coche, y es que también en el control sobre la conducción de un coche se ponen de manifiesto habilidades de algún tipo (habilidades de conducción y todo lo que ellas implican). Si tengo control sobre geografía y sé que la capital de Omán es Mascate es porque tengo una habilidad epistémica relacionada con la geografía. Básicamente, parece que tener control sobre algo que envuelva algún tipo de cognición implica el desempeño de alguna habilidad. Si esto es así, la manera de relacionar la intuición antisuerte y la intuición de la habilidad es muy clara y encaja muy bien.

\section{SUERTE COMO RIESGO}

Algún autor contemporáneo como Jesús Navarro ${ }^{17}$ muestra cómo la noción de riesgo es más explicativa, más parsimoniosa, más precisa, más directiva y más sistemática que la noción de suerte. Lo cierto es que la noción de riesgo es también útil para evitar una actitud neurótica hacia el conocimiento. Esta neurosis queda representada en el momento en el que yo necesito comprobar constantemente mis creencias para saber si son verdaderas y si lo que tengo en la cabeza constituye conocimiento. Por ejemplo, si digo a mi amigo que aquello por lo que me está preguntando no lo tengo ahora en la cabeza, sino que he de esperar a llegar a casa para mirarlo en mi cuaderno, y que después le podré responder, no debo tener miedo por si mi cuaderno va a ser destruido por mi perro en el tiempo que voy a tardar en llegar a casa, ni tampoco adelantar mi marcha, ni nada que se le pueda parecer, sino simplemente asumir de manera implícita que hay un riesgo (muy mínimo) de que eso suceda. En este trabajo vamos a asumir el giro del riesgo planteado por Jesús Navarro, aunque, como veremos, no de la misma manera que él.

17 Jesús Navarro, «Luck and risk: How to tell them apart», Metaphilosophy, vol. 50, n. ${ }^{\circ} 1-2$, 2019, pp. 63-75; y Jesús NaVArro, «Epistemic Luck and Epistemic Risk». 
El giro del riesgo se ha dado también en otros autores como Duncan Pritchard $^{18}$, quien considera que los portadores principales de la suerte (riesgo) epistémica son los eventos, entendidos estos como el paso de un estado de cosas a otro del mundo. Esta posición implica para Pritchard que, aunque hablar de riesgo tiene algunos beneficios epistémicos ${ }^{19}$, en realidad la suerte y el riesgo son movimientos similares solo que vistos desde situaciones temporales distintas. Para Pritchard el hecho de que alguien se salve en una situación muy peligrosa con una avioneta en mal estado puede ser considerado como suerte cuando ya se está en tierra (pues no se ha muerto) o como riesgo antes de subirse (hay un gran riesgo de morir). En el ejemplo de la avioneta, se da la suerte porque había muchos mundos posibles cercanos en los que el agente que subía moría, y se da el riesgo porque antes de subir, hay muchos mundos posibles cercanos en los que se muere. Ambas explicaciones son la misma, pero desde momentos temporales distintos.

Para Jesús Navarro ${ }^{20}$ la cosa es distinta, pues los portadores primarios de suerte no son los eventos, sino los sucesos, que se definen como un estado de cosas del mundo. De este modo, el juicio del riesgo epistémico se entiende como completamente distinto del juicio de la suerte epistémica. Desde un suceso determinado es como se considera cómo de afortunado o relacionado con el riesgo ha sido un determinado suceso y no desde el evento mismo.

Mi posición aquí va a aceptar el giro del riesgo, pero lo va a aceptar considerando que los portadores primarios de suerte epistémica no son los sucesos ni tampoco los eventos, sino los agentes en un sentido similar al de Fernando Broncano-Berrocal, quien afirma que "cualquier evento significativo que es cuestión de suerte es un evento con respecto del cual el agente está en riesgo ${ }^{21}$. Considerar al agente como el portador principal del riesgo epistémico no es baladí, pues es una condición fundamental que permite entender de manera adecuada el funcionamiento de la teoría de la suerte epistémica como carencia de control. Además, esta posición nos permite explicar ejemplos como el siguiente:

\section{Pandemia global}

Considérese que una pandemia global con un índice de mortalidad muy alto se extiende por la Tierra. Se sabe que si una persona tiene más de 60 años, su muerte es segura, pero si tiene menos de 60 puede salvarse. Dos personas, una de más de 60 años (S1) y una de menos de 60 años (S2), tratan de huir del virus y se

18 Duncan Pritchard, «Risk», Metaphilosophy, vol. 46, n. ${ }^{\circ} 3$, 2015, pp. 436-461; y Duncan Pritchard, «Epistemic Risk», Journal of Philosophy, vol. 113, n. ${ }^{\circ} 11,2016$, pp. 550-571.

19 Duncan Pritchard, «Anti-risk epistemology and negative epistemic dependence», Synthese, 2017, https://doi.org/10.1007s11229-017-1586-6.

20 Jesús NaVARro, «Epistemic Luck and Epistemic Risk».

${ }^{21}$ Fernando Broncano-Berrocal, op. cit., p. 21. 
encierran en una casa. Si el virus llegase a la casa donde están encerrados S1 y S2, S1 moriría, pero S2 no.

Creo que es razonable pensar que $S 1$ tiene más riesgo que $S 2$ ante el mismo suceso (estado de cosas del mundo) y también ante el mismo evento (cambio de un estado de cosas a otro). Además de que personas distintas pueden tener distinto riesgo ante el mismo suceso o evento, aceptar que los portadores primarios de suerte y riesgo epistémico (o no epistémico) son los agentes nos da también parámetros que nos permiten guiar de una manera más correcta nuestras acciones, puesto que desde perspectivas que centran la suerte y el riesgo en sucesos y eventos no podemos ser efectivos a la hora de dar apoyo a un determinado sector de la sociedad (los mayores de 60 ańos) antes que a otros (los menores de 60 años) si llegase una pandemia real como la de mi ejemplo. Pienso que considerar como portadores primarios de la suerte y el riesgo a los agentes nos da ventajas también en este sentido.

UN PROBLEMA A RESOLVER EN LA TEORÍA DE LA SUERTE EPISTÉMICA COMO CARENCIA DE CONTROL

Ahora sí, podemos entender de una manera más acertada la posición que explica la suerte epistémica como carencia de control. No obstante, la definición de Broncano-Berrocal de suerte epistémica, aunque extensa, no logra captar como carentes de suerte algunos ejemplos que lo son de manera evidente. Problemas relacionados con el que voy a tratar aquí se han dado ya de manera parecida por parte de Jennifer Lackey ${ }^{22}$, quien afirmaba que, además de los problemas que ya soluciona la definición de Broncano-Berrocal, había otros. Afirma que cuando ella lleva a su hija Isabella al colegio, su marido tiene interés en que su hija llegue sana y salva allí, y carece de control con respecto a ello, pero que el hecho de que llegue sana al colegio no implica que haya sido por una cuestión de suerte. En este mismo sentido podemos plantear un caso similar:

\section{Eva en el $A V E$}

Considérese que Eva ha de viajar de Granada a Madrid y toma el AVE. Eva no es maquinista ni tampoco entiende nada de trenes. Eva, por lo tanto, no tiene control efectivo sobre el tren, ni tampoco está monitoreando al tren. Sin embargo, llega de manera satisfactoria al destino.

¿Consideramos que Eva ha tenido suerte en llegar con vida a Madrid? Lo cierto es que no lo parece. Si consideráramos que Eva ha tenido suerte en tomar el tren y llegar con vida a Madrid, la gente no cogería trenes, porque sentirían que están en riesgo y que es una cuestión de azar (que está fuera de su control) el hecho

${ }^{22}$ Jennifer Lackey, op. cit. 
de llegar con vida o no al destino. Pero lo cierto es que RENFE es una empresa fiable cuyos productos son consumidos habitualmente.

Un ejemplo parecido, pero aplicado a la epistemología, es el siguiente:

\section{Claudia y la capital de Ruanda}

Claudia es una estudiante de $4 .^{\circ}$ de la ESO que tiene algunos problemas para identificar capitales del mundo. Se sabe todas las capitales de Europa pero no conoce ninguna de África. Cada vez que duda sobre cuál es la capital de Ruanda pregunta a su profesora de geografía, a quien considera una informadora fiable en lo que a capitales del mundo se refiere, aunque no es capaz de tener control efectivo ni monitoreado sobre el hecho de que la capital de Ruanda es Kigali.

Parece que hay entonces un problema en la caracterización de la suerte como carencia de control, porque no es suerte que Claudia sepa que la capital de Ruanda es Kigali, ni tampoco es cuestión de suerte que Eva haya llegado con vida a Madrid. Siguiendo esto, no ha sido cuestión de suerte para el marido de Jennifer Lackey que su hija Isabella haya llegado satisfactoriamente al colegio. Parece que la definición aportada por Broncano-Berrocal presenta algunos problemas, lo cuales se intentarán solucionar en el apartado siguiente.

\section{LA CARENCIA DE CONTROL COMO JUSTIFICADOR EXTERNISTA}

Otro debate habitual dentro de la epistemología contemporánea es sobre las posturas internistas y externistas. La cuestión se centra en dos elementos de la epistemología: el conocimiento y la justificación. De este modo, se puede hablar de externismo o internismo en función de si pensamos que la base del conocimiento o los justificadores para sostener una creencia son externos o internos.

La estrategia que se va a seguir aquí es considerar la carencia de control como un justificador para una determinada creencia. De modo que podremos aplicar la teoría actual de la epistemología sobre externismo a la noción de suerte epistémica caracterizada antes y poder así solucionar algunos de los problemas de la definición de Broncano-Berrocal.

\section{DeFINICIÓN DE JUSTIFICADOR}

La primera caracterización sobre los justificadores fue dada por William Alston $^{23}$, quien definió la noción de justificador como todo aquello que afecta a la justificación de una creencia positiva o negativamente. Otras nociones algo más trilla-

${ }^{23}$ William P. Alston, «Internalism and Externalism in Epistemology», Philosophical Topics, vol. 14, n. ${ }^{\circ}$ 1, 1986, pp. 179-221. 
das han sido expuestas en la literatura posterior por figuras como Alvin Goldman ${ }^{24}$, quien afirmaba que un justificador de cualquier creencia o actitud doxástica es una condición, propiedad o estado de hechos que es positiva o negativamente relevante para el estatus justificacional de esa determinada actitud o creencia. La noción de Goldman de relevancia para la creencia o actitud doxástica no es simplemente causal, sino que ha de entenderse como relevante a nivel explicativo. Algo sería relevante, por tanto, si ayuda a explicar por qué alguien tiene un determinado estatus justificacional o por qué ese estatus justificacional es el que es. En su terminología, y en alguna posterior, estos justificadores han pasado a llamarse también factores-J.

En función de lo dicho en el apartado anterior, podemos decir que una persona tiene suerte epistémica siempre y cuando haya tenido una carencia de control en aquello que hace. Del mismo modo, esa persona está en riesgo con respecto a algo para lo que tiene también una carencia de control muy alta (o simplemente una que no estemos dispuestos a admitir) con respecto a una determinada acción. Lo contrario a tener una carencia de control es tener una tenencia de control, algo que se da cuando nuestras acción y creencias están claramente controladas por nosotros. El conocimiento es incompatible con la suerte epistémica de modo que el conocimiento ha de buscar tenencia de control en sus creencias y acciones.

Es en este sentido como se debe entender la tenencia o carencia de control. Según lo expresado por Goldman, un justificador ha de tener relevancia explicativa para el estatus justificacional de la creencia. En tanto que se puede explicar por qué alguien está o no está justificado con respecto a una determinada creencia en función de si ha tenido una carencia o tenencia de control con respecto a esa determinada creencia, podemos afirmar que realmente la tenencia o carencia de control es un justificador (o un factor-J). Una persona puede tener en muy poca estima el estatus justificacional de otra que forma sus creencias a través de métodos para los que no tiene ningún control (tirando un dado para tomar decisiones en su día a día). O al contrario, se le puede dar un gran crédito al estatus justificacional de una persona que se forma una creencia sobre que el árbol que está mirando es un manzano con una base muy fuerte en sus conocimientos de botánica (lo que supone una gran tenencia de control).

Por tanto, la tenencia o carencia de control con respecto a creencias o actitudes es algo que puede fácilmente contar como un justificador para nuestras creencias, en tanto que es relevante para el estatus justificacional de un determinado agente con respecto a un determinado contenido. Esto nos va a permitir aplicar nuestra noción de suerte epistémica al debate en torno al internismo y el externismo.

${ }^{24}$ Alvin Goldman, «Internalism, Externalism, and the Architecture of Justification», The Journal of Philosophy, vol. cvi, n. ${ }^{\circ}$ 6, 2009, p. 311. 
Habitualmente, el internismo había considerado que una persona solo estaba justificada en creer que p si y solo si podía tener acceso por reflexión a una serie de justificadores para esa determinada creencia $\mathrm{p}$ (en su versión más débil). No obstante, algunos de los problemas que esta caracterización acarrea relacionados, por ejemplo, con la toma de decisiones rápidas en momentos de mucha tensión (aterrizaje forzoso y satisfactorio de un avión) hacen que la propuesta internista tenga que ser modificada ${ }^{25}$.

La modificación se ha dado en muchas ocasiones a través del mentalismo, o sea, a través de la idea de que la justificación de una creencia se basa en alguno de los estados mentales (conscientes o inconscientes) que el agente que tiene la creencia posee. También la modificación se ha realizado por la vertiente deontológica, afirmando que estar justificado en creer $\mathrm{p}$ es tener permiso para creer $\mathrm{p}$, mientras que no estar justificado es no tener permiso. De esta posición se derivan algunas obligaciones y responsabilidades a la hora de creer o no creer p, por lo que se presupone que tienen acceso a sus justificadores para evaluar si deben o no deben tener su creencia p, siendo este el punto internista de la posición deontológica. Estas dos posturas hacen depender la justificación, en resumen, de que el agente tenga o pueda tener acceso a sus estados mentales o disposiciones, con el fin de justificar una determinada creencia.

Otros autores han defendido la existencia de justificadores externos al propio agente, a pesar de que la posición predominante a lo largo de la epistemología ha sido la internista (algo que ha cambiado en estos últimos años). En general, una posición de estas características es exitosa con el mero hecho de que exista algún justificador externo, negando así el mentalismo o la actitud deontológica (y negando, en definitiva, que todos los justificadores para una determinada creencia deban buscarse en disposiciones internas del propio individuo). Goldman ${ }^{26}$ expone el modo de acción habitual del internismo para criticar la vía deontológica:

1. Primero se da una guía deontológica de la concepción de la justificación.

2. Después se da una restricción de los determinadores de la justificación, afirmando que todos deben ser accesibles o conocidos por el agente epistémico.

3. Por último, se postula que la accesibilidad o el conocimiento solo se da a través de factores internos.

Sin embargo, Goldman afirma que ninguna de las restricciones que da un internista son aceptables, de modo que tanto la versión fuerte del internismo como

${ }_{25}$ George Pappas, «Internalist vs. Externalist Conceptions of Epistemic Justification», Stanford Encyclopedia of Philosophy, 2014, https://plato.stanford.edu/entries/justep-intext/. [Consultado el 17 de abril de 2020].

${ }^{26}$ Alvin Goldman, «Internalism Exposed», The Journal of Philosophy, vol. 96, n. ${ }^{\circ}$ 6, 1999, pp. 271-293. 
la versión débil deben ser abandonadas. La versión fuerte afirma que solo hechos concernientes a estados conscientes de un agente en un momento t son justificadores de la creencia del agente en t. Esta versión no se sostiene debido a la memoria profunda, que muestra cómo no debemos ser siempre conscientes de nuestros justificadores ya que hay cosas que hemos podido aprender hace mucho tiempo pero de las que no somos conscientes ahora, aunque se quedan grabadas en nosotros. La versión débil, que afirma que solo hechos conscientes y/o estados mentales almacenados en un momento $t$ son justificadores de la creencia del agente en $t$, es anulada a través del problema de la evidencia olvidada, puesto que no diríamos que alguien que se ha aprendido todas las capitales del mundo mirando en un atlas de geografía, pero que en un momento determinado olvida que ha mirado dichas capitales en el atlas, no está justificado en creer que Antananarivo es la capital de Madagascar.

Por otro lado, Srinivasan $(2018)^{27}$ ha señalado cómo algunos de los ejemplos paradigmáticos contra el externismo pueden ser reformulados como contraejemplos al internismo. Además, según la autora, el internismo explica peor casos donde hay una mala ideología. Esto se muestra claramente en ejemplos como el de la cena racista donde una chica árabe (Nour) es invitada por su amigo blanco e inglés a cenar a su casa. En la comida todo parece transcurrir con normalidad, pero cuando Nour se va de casa tiene una extraña sensación de que el padre de su amigo es racista. Ella no puede explicar por qué lo cree, no puede dar ninguna justificación para su creencia, simplemente siente que lo ha sido. De hecho, el padre de su amigo es racista, y piensa que las personas árabes son inferiores a las personas no árabes.

Lo único que podemos decir, según Srinivasan, para mostrar por qué Nour se ha dado cuenta de que el padre de su amigo es racista, es que tiene una sensibilidad especial hacia el racismo, algo que le permite captar en la mayoría de las ocasiones en las que alguien es racista que eso es racismo. ¿Diríamos que la creencia de Nour está justificada? Srinivasan cree que lo haríamos y apela a un justificador: no ha sido cuestión de suerte que Nour capte el racismo. Esto significa, siguiendo a este trabajo, que Nour tiene control sobre su creencia de que el padre de su amigo es un racista porque no ha formado su creencia a través de algo azaroso, sino a través de su especial y acertada sensibilidad hacia el racismo.

Debido a consideraciones como estas creo posible que un justificador sea externo. El internismo, como se ve en Goldman, da problemas cuando aporta sus restricciones, además de no ser capaz de explicar casos en los que hay involucrada mala ideología (como el caso de Nour y la cena racista) o simplemente casos donde la toma de decisiones ha de ser rápida y no mediada por reflexión (como en un aterrizaje forzoso). En definitiva, creo haber referido a suficientes razones como para defender que mi enfoque metodológico sea externista, que considera (habitualmente) como justificada una creencia que se obtiene a través de un determinado método fiable, esto es, que da resultados correctos de manera habitual.

27 Amia SRInivasan, «Radical Externalism», en prensa, 2018, https://philpapers.org/go.pl?i$\mathrm{d}=$ SRIRE\&aid=SRIREv1. 
Partiendo de que la tenencia y carencia de control es un justificador, y de que los justificadores pueden ser externos al agente, ¿cómo sería una carencia de control externista?

En la caracterización de Broncano-Berrocal ${ }^{28}$, como hemos visto anteriormente, «A tiene control efectivo sobre B si y solo si (i) es un objetivo de A que B esté en un cierto estado $S$, (ii) A está en disposición de llevar a B a $S$, y (iii) B está en $S$ por la disposición de A de llevar a B a $S_{»}$, siendo un caso paradigmático el de un conductor de coche que lleva su vehículo hasta una determinada posición distinta a la que estaba en un inicio. Además, en el control monitoreado "A tiene control sobre B si y solo si A monitorea a B. Monitorear tiene 2 componentes. Cuando A monitorea a B, A registra información sobre $\mathrm{B}$. Esta es la información epistémica $\mathrm{o}$ componente informacional del monitoreo. Además, la información que A registra sobre $\mathrm{B}$ permite a A iniciar, parar o continuar alguna acción que contribuya a un objetivo relevante ${ }^{29}$, siendo un caso paradigmático el de un médico que da tratamiento a un paciente enfermo y sobre el que tiene capacidad de aplicarle un tratamiento cuando sea necesario.

Pienso que es posible entonces dar una nueva opción de control que no está planteada por Broncano-Berrocal y que tiene un marcado cariz externista. Este nuevo control tendría una forma como esta: A también tendría control sobre B para dejarlo en una posición $S$ si A deja a $B$ en $S$ a través de un mecanismo confiable (entendiendo confiable como dando resultados adecuados de manera repetida). A no deja a $B$ en $S$ a través de su propia e interna condición, sino que deja que un mecanismo externo a sí mismo coloque a B en S. Esto significa, en nuestro ejemplo del tren, que Eva no ha tenido suerte en llegar con vida a Madrid, sino que tenía un determinado control externista al dejar que el propio tren la llevase a Madrid confiando en toda la infraestructura fiable de RENFE (maquinista, encargados de las vías...). Del mismo modo, en el ejemplo de Lackey, tampoco su marido ha tenido suerte en que su hija Isabella llegase con vida al colegio, porque un modo de tener control sobre algo es tener un método confiable. Del mismo modo, Claudia tiene control sobre su conocimiento de que la capital de Ruanda es Kigali en la medida en que preguntarle a su profesora es un método fiable para saber la capital de Ruanda. Claudia no tiene ningún justificador interno (estado mental, actitud doxástica...), sino solo justificadores externos como su profesora de geografía, que es un mecanismo confiable a la hora de consultar las capitales de los distintos países de África.

Este es el modo como se soluciona el problema planteado en el apartado anterior. Así pues, no puede ser considerado una cuestión de suerte el que alguien obtenga una creencia utilizando un método confiable que acierta en una gran mayoría

\footnotetext{
${ }^{28}$ Fernando Broncano-Berrocal, op. cit., p. 18.

${ }^{29}$ Ibid., pp. 18-19.
} 
de las ocasiones. El hecho de saber recurrir a esos determinados métodos confiables implica tener también una buena habilidad justificadora, además de un determinado conocimiento práctico.

\section{APLiCACIÓN DE LA NUEVA CARACTERIZACión A LA GENEALOGÍA DE LA SUERTE}

Amia Srinivasan ${ }^{30}$ ha tratado el problema del escepticismo genealógico relacionándolo con la suerte epistémica. El escepticismo genealógico se basa en afirmar que todos nuestros compromisos epistémicos son contingentes en el sentido en que podrían haber sido de cualquier otra manera si nosotros hubiésemos tenido otra cultura, otro lenguaje, otra educación, etcétera. Supongamos, como nos propone Srinivasan, que la gente que comulga con una filosofía oriental piensa que Jones, en el caso de Gettier, sí conoce, mientras que la gente que comulga con la filosofía occidental no. ¿Significa esto que mi creencia de que Jones no conoce no está justificada? ¿Y si a todos mis compromisos filosóficos les pasase lo mismo? Este tipo de preguntas son parte de lo que Srinivasan llama ansiedad genealógica, que solo puede eliminarse solucionando el problema del escepticismo genealógico.

Todos los argumentos para el escepticismo genealógico (insensitividad, relevancia explicativa, coincidencia e improbabilidad evidencial) se contradicen a sí mismos, incluido el mejor de ellos (falta de fiabilidad) ${ }^{31}$, que afirma que no hay evidencia de que nuestros juicios sean seguros, o sea, que estos podrían haber sido fácilmente de otra manera si seguimos un procedimiento similar. En cualquier caso, el escepticismo parece que sigue vivo aunque se contradiga a sí mismo, y prueba de ello es la ansiedad que nos asalta con respecto a nuestras genealogías. Es por ello que Srinivasan piensa que debemos poner un suelo firme en el que pisar: el ser beneficiarios de una suerte genealógica. Es cierto que hay otras posibles soluciones (antirrealismo con respecto a las verdades filosóficas o un cambio radical de la noción de creencia) que plantea la propia Srinivasan, pero la mención a la suerte genealógica es algo que entra de golpe dentro del trabajo aquí presentado.

Ser beneficiarios de suerte epistémica pretende solucionar el problema de la indiferencia aletheica, basada en la afirmación de que nuestras creencias son producidas por un mecanismo causal del que no tenemos razón independiente para creer que producirá verdades sobre problemas relevantes. Esta última idea es el fundamento de todo escepticismo genealógico y oponerse a ella es una de las estrategias existentes para negarlo. Srinivasan, en vez de seguir esta vía, prefiere sostener que somos beneficiarios de una determinada suerte genealógica, que nos permite afirmar que, simplemente, y de manera completamente casual, nuestros juicios filosó-

30 Amia Srinivasan, "The Archimedean Urge», Philosophical Perspectives, n. . 29, 2015, pp. 325-362; y Amia Srinivasan, «Genealogy, Epistemology and Worldmaking», Aristotelian Society, vol. CXIX, parte 2, 2019, pp. 127-156.

31 V. Amia Srinivasan, «The Archimedean Urge». 
ficos contactan con las verdades filosóficas. Dicho de otro modo, ser beneficiario de suerte genealógica implica aceptar que nuestra genealogía es la correcta en contraposición con otro tipo de genealogías. Los procedimientos a través de los cuales una persona se forma una creencia no son seguros, y si esa persona hubiese nacido en un lugar diferente al lugar en el que nació, no tendría las mismas creencias. Así, la creencia de que estoy en mi habitación es justificada a través de mis percepciones sensoriales, pero esto será verdadero únicamente porque no soy un cerebro en una cubeta (debido a una cuestión de suerte). Nuestras creencias podrían haber sido fácilmente creencias falsas debido a un cambio en nuestra genealogía, pero es cuestión de suerte que no haya sido así.

No obstante, para Srinivasan, eso no quiere decir que mis creencias genealógicas no sean verdadero conocimiento ni tampoco que todas sean igual de válidas. Hay, en ocasiones, modos de comparar entre dos genealogías diferentes, a través de diversos métodos que pueden demostrar que una genealogía es mejor que otra. Por ejemplo, la medicina de los humores, que se mantuvo desde Hipócrates hasta el siglo XVIII, fue una teoría sustentada por una determinada genealogía, mientras que la medicina contemporánea mantiene otra. Supongamos que en la época de Hipócrates un infarto se trataba realizando un sangrado, mientras que en la actualidad hay otra serie de mecanismos informatizados, que permiten que la persona infartada reciba otro tratamiento más efectivo. Tenemos mecanismos para decidir entre ambas genealogías, y podemos saber que la actual es mejor que la de Hipócrates puesto que es más efectiva a la hora de tratar a enfermos. Si yo hubiese nacido en la Grecia Clásica y fuese médico, trataría los infartos a través de sangrados, pero no es así por una cuestión de suerte. Sin embargo, tengo argumentos alternativos a la apelación a mi genealogía que me permiten saber que es mejor que la de Hipócrates, y eso ya no es una cuestión de suerte (porque tengo control, y por tanto justificación sobre mis creencias). Yo no tengo las creencias que tengo con respecto a la genealogía médica de una manera arbitraria, sino que soy capaz de argumentar que mi genealogía es mejor porque da mejores resultados (mayor esperanza de vida, procedimientos más racionales en base al conocimiento disponible en otras esferas...) que la hipocrática de manera continuada. No tengo, por lo tanto, un control monitoreado o efectivo sobre mi genealogía, sino uno externista, en tanto que confío en los habituales buenos resultados que mi genealogía produce con respecto a otras y eso hace que mis creencias puedan constituir conocimiento.

No obstante, hay casos en los que no se puede ir más allá de nuestra propia genealogía, casos en los que no hay criterios intermedios que permitan una comparativa entre dos genealogías. Un caso evidente es el de los dogmas. No hay, en principio, motivos para que una persona cristiana intente convencer a una persona musulmana de que su genealogía es mejor. No pueden apelar a nada más que a la propia genealogía, puesto que sus posicionamientos religiosos se basan en una cuestión de fe y ninguna de las dos genealogías, tomadas en sí mismas, da mejores soluciones de manera continuada. En casos como este, las personas no tienen verdadero control (en ninguna de sus tres formas) sobre sus creencias, y en el caso en el que sus creencias fuesen verdaderas, no constituirían conocimiento, puesto que hay en juego una determinada suerte epistémica. Si en casos como el anterior, el 
proceso de formación de la creencia se basa solo en la genealogía recibida (y no en algún tipo adicional de control externista), entonces la creencia no está justificada.

Un tema que Srinivasan relaciona con este es el de las genealogías críticas, que pueden ayudar a entender cómo se puede construir mundo y hacer política desde la filosofía. Srinivasan ${ }^{32}$ afirmará que la genealogía de la moral nietzscheana no es solamente una revisión histórica que muestra que el sistema moral cristiano de la filosofía occidental es algo engañoso porque depende, por ejemplo, de la moral del amo y el esclavo que vamos acarreando desde hace mucho tiempo. No muestra por tanto Nietzsche que la moral cristiana sea falsa en un sentido proposicional, sino que emprende la tarea de construir un nuevo mundo, una nueva moral que, justificada de manera externista, es mejor que la genealogía anterior. Catherine A. MacKinnon ${ }^{33}$ también realiza a juicio de Srinivasan una tarea parecida, puesto que confronta dos tipos de genealogías de las mujeres. La construcción del nuevo mundo se da entonces en el abandono de la construcción de las mujeres a través del hombre para construir a las mujeres desde sí mismas, algo que daría mejores resultados para el bienestar de las mujeres y que conformaría, en un sentido también externista, un sistema mejor que el patriarcal.

Por lo tanto, nuestra tercera vía de control puede explicar cómo (en línea con Srinivasan), a pesar de que nuestras creencias genealógicas podrían haber sido otras, no podemos decir que no constituyan conocimiento. Podemos pensar que somos beneficiarios de una determinada suerte genealógica a pesar de que en ocasiones tengamos mecanismos que nos permitan estar justificados con respecto a nuestra genealogía $a^{34}$. Estos mecanismos que permiten la justificación genealógica son en muchas ocasiones mecanismos externistas sobre los que tenemos control, puesto que dan mejores resultados (en algún sentido) que otros. Nuestra justificación, por lo tanto, no es meramente genealógica y evita la suerte epistémica a través de nuestro tercer tipo de control. Es por lo tanto aquí donde nuestra reformulación de la suerte epistémica como carencia de control y su vertiente externista arroja luz en otros campos de la filosofía y la epistemología.

\section{CONCLUSIÓN}

En la primera parte se ha demostrado que la visión modal y la probabilística son peores aproximaciones a la suerte epistémica, puesto que no son capaces de explicar algunos contraejemplos importantes. Por ello, se ha elegido una aproximación a la suerte epistémica como carencia de control, que permite, además, relacionar de manera más evidente las dos intuiciones de la epistemología. Además, esta aproxi-

32 Amia Srinivasan, «Genealogy, Epistemology and Worldmaking».

${ }_{33}$ V. Catharine A. MacKinnon, «Feminism, Marxism, Method, and the State: Toward Feminist Jurisprudence», Signs, 8, 4, 1983, pp. 635-658.

${ }_{34}$ Prueba de esto es que podemos luchar contra nuestras propias genealogías, como los hombres que intentan deconstruir su educación basada en el machismo. 
mación se ha entendido como formando parte del giro del riesgo, aunque considerando que los portadores principales del riesgo son los agentes, de modo que cualquier evento afortunado puede ser considerado algo para lo cual el agente está en riesgo. No obstante, esta aproximación también presentaba un problema, que ha sido solucionado en el apartado siguiente, permitiendo otro tipo distinto de control al entender la carencia de control como un justificador y adoptando una posición metodológica externista. Esta reformulación de la noción inicial dada por Broncano-Berrocal no solo tiene la ventaja de salvar algunos contraejemplos, sino que tiene capacidad explicativa, como se ha visto en su aplicación a la genealogía de la suerte.

Recibido: noviembre de 2020; ACEPTADo: abril de 20021 